\title{
CÉLULAS PROGENITORAS ADULTAS MULTIPOTENTES ALOGÊNICAS NO TRATAMENTO DE DOENÇA RENAL EM FELINOS
}

\author{
SANTOS, Enrico Jardim Clemente ${ }^{1}$; \\ POPPI, Fabiana Pozzuto ${ }^{2}$; \\ BRAGA, Camila Landim ${ }^{3}$.
}

${ }^{1}$ Biotecnólogo, Mestre, Doutor, Pesquisador, terapia com células tronco, medicina regenerativa, engenharia tecidual; ${ }^{2}$ Médica Veterinária, Mestranda, FCAV/UNESP Jaboticabal; ${ }^{3}$ Médica Veterinária, Especialista em nefrologia veterinária.

\section{RESUMO}

\begin{abstract}
A doença renal crônica (DRC) é uma síndrome caracterizada pelo comprometimento do metabolismo renal, que ocorre de forma dinâmica e progressiva, culminando na perda das funções fisiológicas dos rins. As células progenitoras adultas multipotentes (CPAM), presentes em todos os tecidos que constituem o organismo, têm como caracteríticas principais o seu potencial de autorenovação e diferenciação celular. Quando introduzidas no organismo as CPAM adquirem a morfologia e funcionalidade de qualquer tipo celular que constitui o tecido lesado, o que tem levado a sua utilização terapêutica na medicina veterinária. Neste estudo, sete felinos sem distinção de raça e sexo, com idades entre 4 e 13 anos, acometidos pela DRC estágio 2, foram tratados com células progenitoras adultas multipotentes de tecido adiposo de felinos (CPAMs-TAF), oriundas de um animal doador saudável. Foram realizadas três infusões pela via endovenosa, com intervalo médio de 30 dias. Os pacientes demonstraram uma significativa melhora da função renal após as infusões das CPAMs-TAF sem aparentes efeitos adversos, tendo sido observada uma melhora clínica, ganho de apetite e aumento da disposição já após a primeira aplicação. Conclui-se que a terapia com as CPAMs-TAF colaborou significativamente para a melhoria da qualidade de vida dos felinos acometidos pela DCR estágio 2.
\end{abstract}

Palavras-chave: CPAMs. Insuficiência renal. Gato. Terapia celular. 


\section{INTRODUÇÃO}

A doença renal é uma patologia de alta incidência em gatos, causando consideráveis índices de morbidade e mortalidade (GRAUER, 2005). Esta síndrome se caracteriza pelo comprometimento do metabolismo renal, que ocorre de forma dinâmica e progressiva por períodos que variam de meses a anos, culminando na perda das funções fisiológicas dos rins. Estes são responsáveis por filtrar o sangue, a fim de excretar resíduos metabólicos e liberar hormônios que têm papel vital no controle da pressão arterial sistêmica e na produção de glóbulos vermelhos (PRESSLER, 2013).

As terapias convencionais para o tratamento da doença renal incluem, principalmente, a fluidoterapia, orientação dietética e diálise, as quais visam promover uma melhora na qualidade de vida do paciente (FISCHER et al, 2004; QUEIROZ, 2013). Entretanto, mesmo utilizando-se das terapias conservativas, a injúria estrutural tende a evoluir, favorecendo a redução da massa renal e consequentemente a falência do órgão. O transplante renal, procedimento pouco explorado e bastante incomum na medicina veterinária, consiste atualmente no único método que favorece a melhora total do paciente (HOPPER et al., 2012).

Embora preconiza-se a importância do diagnóstico precoce, são baixos os índices do mesmo na fase inicial da doença renal, pois a manifestação dos sinais clínicos característicos tende a ocorrer em estágios mais avançados (BARBER, 2003). Devido aos aspectos restritivos, o prognóstico a longo prazo tem se mostrado desfavorável (BARBER, 2003). Na medicina veterinária busca-se um tratamento que, juntamente com a terapia convencional, possa ser mais efetivo, melhorando a qualidade de vida e aumentando a sobrevida destes pacientes.

A doença renal pode ser classificada em aguda ou crônica. A insuficiência renal aguda (IRA) é caracterizada pela rápida perda de função dos néfrons, resultando em azotemia e/ou aparecimento de alterações em fluidos e eletrólitos. A diminuição da função renal que ocorre na IRA é multifatorial e inclui diminuição do fluxo sanguíneo intra-renal e danos celulares (ETTINGER; FELDMAN, 2004). Já a insuficiência renal crônica (IRC) resulta de lesões renais irreversíveis e progressivas que tornam o rim incapaz de realizar as suas funções. 0 ritmo de progressão depende da doença original e causas agravantes como hipertensão, 
infecção urinária, nefrite, diabetes, dentre outras (MCGROTTY, 2008). A padronização das lesões levou a International Renal Interest Society (IRIS, 2017) a propor um sistema de classificação composto por quatro estágios, os quais são amplamente utilizados pela comunidade médica veterinária.

As células progenitoras adultas multipotentes (CPAMs), mais comumente conhecidas como células-tronco mesenquimais (CTM), estão presentes em todos os tecidos que constituem o organismo, sendo caraterizadas com base no seu potencial de autorenovação e diferenciação celular. Além disso, são responsáveis por assegurar a homeostase do tecido durante o transcorrer da vida do animal (CAPLAN; DENNIS, 2006). As CPAMs apresentam um grande número de moléculas bioativas, que atuam modulando a resposta inflamatória, angiogênese e mitose das células envolvidas no processo de reparação tecidual. Quando introduzidas no organismo adquirem tanto a morfologia como a funcionalidade de qualquer tipo celular que constitui o tecido lesado. Estudos vêm relatando que grande parte das CPAMs transplantadas tendem a não serem integradas ao tecido lesionado, mas sim exercem seu efeito terapêutico nas CPAMs endógenas ao tecido injuriado por meio da secreção de diversos fatores tróficos. Desta forma, as CPAMs endógenas são as responsáveis por fornecer suporte ao processo de reparação tecidual por meio dos mecanismos de diferenciação celular, modulação do sistema imunológico, renovação celular, ação antiapoptótica e anti-fibrótica, além de estimular a angiogênese (CAPLAN; HARIRI, 2015). Na medicina veterinária as CPAMs vêm sendo utilizadas tendo sua segurança e eficácia demonstrada em estudos relacionados à diversas patologias, dentre as quais osteoartrites, lesões tendíneas, fraturas, dentre outras (SANTOS, 2017).

Devido ao fato dos néfrons serem de origem mesodermal, a utilização de CPAMs adultas exógenas tornou-se extremamente atrativa quanto ao potencial de reparo renal (SUZUKI et al., 2016). Embora os mecanismos envolvidos na diferenciação das CPAMs in vivo ainda não tenham sido plenamente entendidos, sabe-se que estas atuam modificando o microambiente através da secreção de fatores parácrinos e/ou endócrinos que potencializam a reparação tecidual, atribuindo-se o potencial reparativo à capacidade proliferativa das CPAMs, plasticidade, processos de sinalização celular, produção de 
biomoléculas, fatores de crescimento e moduladores da resposta imune (CAPLAN; HARIRI, 2015).

Dados experimentais em ratos sugerem que a administração exógena das CPAMs durante as lesões renais crônicas e agudas pode resultar em uma melhora funcional e uma recuperação estrutural ao nível tubular, glomerular e intersticial dos rins (PENG et al., 2013). Para tal, as CPAMs são expostas a diferentes mecanismos de ação os quais incluem: a) incorporação das CPAMs ao tecido ou órgão danificado e sua diferenciação no mesmo, de forma a substituir as células lesadas (COLLETTI et al., 2009); b) fusão terapêutica na qual as CPAMs se fusionam com as células adultas diferenciadas resultando em uma célula madura com o fenótipo desejado (QUIJADA et al., 2015); c) liberação de fatores parácrinos e/ou endócrinos (QIN et al., 2012); d) estimulação do reparo endógeno pela atuação das CPAMs residentes no local lesado as quais são estimuladas pela atividade parácrina das CPAMs exógenas (DONG; CAPLAN, 2012).

Embora os mecanismos que levem as CPAMs a atuarem de forma protetora na lesão renal ainda não tenham sido esclarecidos, tem sido demonstrado claramente que as CPAMs são responsáveis pela mediação da angiogêneses, supressão da inflamação e melhoria da função renal por meio da ação parácrina e/ou endócrina (BUSSOLATI et al., 2008). Desta forma, as pesquisas envolvendo a utilização das CPAMs em doença renal se apresentam extremamente promissoras.

O objetivo deste estudo foi determinar a eficácia do tratamento com células progenitoras adultas multipotentes alogênicas derivadas de tecido adiposo de felino (CPAMs-TAF) e expostas ao processo de criopreservação, na insuficiência renal crônica, estágio 2, e a subsequente melhora na qualidade de vida dos felinos.

\section{MATERIAL E MÉTODOS}

\section{Seleção de animais doadores de tecido adiposo para o tratamento alogênico}

Os animais foram selecionados a partir de populações de pacientes de clínicas veterinárias da cidade de São Paulo mediante o consentimento livre e esclarecido por parte dos 
proprietários. As CPAMs utilizadas no presente estudo foram obtidas a partir de animais jovens, saudáveis e com até seis meses de vida.

\section{Seleção de animais para o estudo}

Foram submetidos ao estudo piloto sete gatos (um Persa, um Siamês e cinco SRD), sendo três machos e quatro fêmeas, com idades variando de 4 anos e 7 meses a 13 anos e 3 meses, pesando de $4 \mathrm{Kg}$ a $6 \mathrm{Kg}$, acometidos pela doença renal crônica, estágio 2, segundo a International Renal Interest Society (IRIS, 2017). Os pacientes para pré-tratamento foram avaliados por meio do perfil hepático (ALT e FA); função renal (ureia, creatinina, albumina, sódio, potássio e cálcio); eritrograma, leucograma, radiografia torácica e ultrassonografia abdominal. Pacientes acometidos por neoplasma, ureterolitíase, pielonefrite ou outro quadro infecioso, rim policístico, hipertensão ou hipotensão ou com ureia acima de 180 $\mathrm{mg} / \mathrm{dL}$ foram excluídos do estudo. Todos os felinos apresentavam um quadro clínico e laboratorial estável há pelo menos duas semanas.

\section{Análise Molecular}

Foi coletada uma amostra de sangue para a análise da presença de coronavírus felino (FCoV), vírus da imunodeficiência felina (FIV), vírus da leucemia felina (FeLV), Chlamydia psittaci (CPS), herpes vírus felino (FHV-1), calicivírus felino (FCV), Haemobartonella felis (HFE) e micoplasma através da amplificação de fragmentos dos respectivos genomas pelo método da reação em cadeia da polimerase (PCR) em materiais extraídos (RNA e DNA). Os RNAs foram extraídos com Trizol LS (Invitrogen ${ }^{\circledR}$ ) e utilizados para síntese de cDNA através de transcrição reversa com superscript II (Invitrogen ${ }^{\circledR}$ ). DNAs foram extraídos utilizando-se o DNAzol (Invitrogen $\left.{ }^{\circledR}\right)$. Foram submetidas a cada pesquisa duas amostras extraídas, controles positivos e negativos.

\section{Isolamento e caracterização das CPAMs-TAF}

O tecido adiposo obtido no momento da castração foi lavado em PBS 1x (phosphate buffered saline) de forma a retirar sangue e debris. Após a lavagem o tecido foi mantido durante 30 minutos a $37{ }^{\circ} \mathrm{C}, 5 \%$ de $\mathrm{CO}_{2}$ em presença de $0,075 \%$ de colagenase tipo IV (Sigma-Aldrich ${ }^{\circledR}$ ). Foi adicionado $5 \mathrm{~mL}$ de meio basal, sendo o sobrenadante retirado e centrifugado durante 5 
minutos a $200 \times$ g. O precipitado foi suspenso e transferido para uma garrafa de cultivo de 25 $\mathrm{cm}^{2}$ a qual foi mantida a $37{ }^{\circ} \mathrm{C}, 5 \% \mathrm{CO}_{2}$ durante 48 horas em presença de meio basal quando o mesmo foi trocado. Os repiques subsequentes foram feitos por meio de ação enzimática utilizando 0,025\% de tripsina (Invitrogen ${ }^{\circledR}$ ). As CPAMs foram divididas em alíquotas de $2 \times 10^{6}$, suspensas em meio de congelamento ( $10 \%$ de DMSO, $70 \%$ de soro fetal bovino e $20 \%$ de meio basal contendo $2 \times 10^{6}$ CPAMs) e armazenadas em nitrogênio líquido. As CPAMs foram administradas com menos de 1 ano de armazenamento. Para serem aplicadas nos felinos, as células foram descongeladas e o meio de criopreservação removido.

Para a análise proliferativa foi isolada uma colônia das CPAMs-TAF expandida até atingir uma confluência de $70 \%$ em uma placa de $25 \mathrm{~cm}^{2}$. As células foram removidas por meio de ação enzimática (tripsina $0,025 \%$, Invitrogen ${ }^{\circledR}$ ) e distribuídas, em duplicatas, sobre placas de 60 $\mathrm{cm}$ na concentração de $10^{5}$ células. Após 48 horas de cultivo, as células foram removidas e replaqueadas. O processo foi repetido até a $10^{\mathrm{a}}$ passagem. A viabilidade celular foi determinada por meio da análise por azul de Tripan, evidenciando uma taxa de $97 \%$ de células viáveis.

O potencial osteogênico das CPAMs-TAF foi demonstrado por meio da coloração de Von Kossa, após as células terem sido mantidas em cultura durante 21 dias em presença do meio de diferenciação osteogênico (Dulbecco's Modified Eagle's Medium - Low Glucose, Invitrogen ${ }^{\circledR}$ ), $1 \%$ de $10^{-5} \mathrm{M}$ de dexametasona (Sigma-Aldrich ${ }^{\circledR}$ ), 1\% $5 \mathrm{mM}$ de ácido ascórbico (Sigma-Aldrich ${ }^{\circledR}$ ), 10\% de soro fetal bovino $\left(\right.$ HyClone $^{\mathrm{TM}}$ ) e $1 \%$ de Penicillin-Streptomycin (penicilina G $10.000 \mathrm{UI} / \mathrm{mL}$, estreptomicina $10.000 \mu \mathrm{g} / \mathrm{mL}$, Invitrogen ${ }^{\circledR}$ ). A troca do meio foi realizada a cada 3 ou 4 dias. No 10을 dia foi adicionado $1 \%$ de $200 \mathrm{mM}$ de $\beta$-glicerolfosfato (Sigma-Aldrich ${ }^{\circledR}$ ). Para a análise do potencial de diferenciação adipogênico as CPAMs-TAF foram cultivadas em meio de diferenciação adipogênico (Dulbecco's Modified Eagle's Medium - Low Glucose, Invitrogen ${ }^{\circledR}$ ), $10 \%$ de soro fetal bovino (HyClone ${ }^{\mathrm{TM}}$ ), $1 \mathrm{mM}$ de dexametasona (Sigma-Aldrich ${ }^{\circledR}$ ), $100 \mathrm{mM}$ de endomentacina (Sigma-Aldrich ${ }^{\circledR}$ ), 0,5 M de isobutilmetilxantina (Sigma-Aldrich ${ }^{\circledR}$ ) $+10 \mu \mathrm{M}$ de insulina (Sigma-Aldrich ${ }^{\circledR}$ ) e 1\% de PenicillinStreptomycin (penicilina G $10.000 \mathrm{Ul} / \mathrm{mL}$, estreptomicina $10.000 \mu \mathrm{g} / \mathrm{mL}$, Invitrogen ${ }^{\circledR}$ ), durante 21 dias e marcadas com Oil Red $O$ (Sigma-Aldrich ${ }^{\circledR}$ ). O potencial de diferenciação 
condrogênico foi demonstrado por meio da marcação por azul de toluidina (Sigma-Aldrich ${ }^{\circledR}$ ) após as CPAMs-TAF terem sido cultivadas durante 21 dias em presença do meio de diferenciação condrogênica (Dulbecco's Modified Eagle's Medium - High Glucose, Invitrogen ${ }^{\circledR}$ ) suplementado com $1 \%$ de soro fetal bovino $\left(\right.$ HyClone $\left.^{T M}\right), 6,25 \mathrm{mM}$ de insulina $\left(\right.$ Sigma-Aldrich $^{\circledast}$ ), 0,1 mM de dexametasona (Sigma-Aldrich ${ }^{\circledR}$ ), $1 \mathrm{mM}$ de piruvato de sódio (Invitrogen ${ }^{\circledast}$ ), $10 \mathrm{ng} / \mathrm{mL}$ TGF- $\beta 1$ (R\&D System, LGC Biotechnology) e 1\% de PenicillinStreptomycin (penicilina G $10.000 \mathrm{UI} / \mathrm{mL}$, estreptomicina $10.000 \mu \mathrm{g} / \mathrm{mL}$, Invitrogen ${ }^{\circledR}$ ).

\section{Aplicação de CPAMs}

Os pacientes foram submetidos a três aplicações com CPAMs alogênicas com intervalo médio de 30 dias entre cada uma. As aplicações foram realizadas pela via endovenosa (veia cefálica), sem sedação. Foi utilizada a dose de 4 × $10^{6}$ CPAMs-TAF alogênicas.

\section{Monitoramento clínico dos animais tratados}

Os gatos tratados no presente estudo foram submetidos a exames clínicos e laboratoriais (ureia, creatinina, fósforo, albumina, sódio, potássio, cálcio e hemograma). Os exames foram realizados anteriormente a cada uma das três aplicações e 180 dias após a terceira aplicação. O procedimento foi aprovado pelo Comitê de Ética no Uso de Animais da CELLTROVET sob o número 9/2016.

\section{Análise Estatística}

Os valores seriados tanto da creatinina quanto da ureia dos gatos submetidos as doses de CPAMs-TAF foram analisados através do teste ANOVA (GraphPad, La Jolla, CA, USA).

\section{RESULTADOS E DISCUSSÃO}

A terapia celular com CPAMs vem mostrando-se extremamente promissora no tratamento ou melhoria da qualidade de vida de diferentes doenças que acometem tanto grandes como pequenos animais. Seu potencial reparativo permite que uma vez introduzidas no organismo, adquiram tanto a morfologia como a funcionalidade de qualquer tipo celular danificado que constitua o tecido lesionado (SANTOS, 2017). 
Estudos realizados em roedores vêm sugerindo serem as CPAMs uma nova opção terapêutica para os felinos acometidos pela doença renal crônica. Em roedores, a administração das CPAMs vem resultando em uma melhora da função renal principalmente devido a redução da inflamação intra-renal e supressão da fibrose por meio de sue efeito parácrino (CALDAS et al., 2015; LEE et al., 2010; REINDERS et al., 2014; SEMEDO et al., 2009).

No presente estudo, as CPAMs isoladas a partir do tecido adiposo de felinos jovens e saudáveis, foram caracterizadas com base em sua capacidade de adesão ao plástico, morfologia fibroblastoide (Figura 1A), capacidade de diferenciação osteogênica (Figura 1B), condrogênica (Figura 1 C) e adipogênica (Figura 1D) além de alto potencial de proliferação celular (Figura 2) (MARTIN et al., 2002). Foi observado um crescimento exponencial até a 9ạ passagem, após a qual identificou-se uma manutenção na curva de crescimento. Quando injetadas em camundongos nude, as CPAMs-TAF não foram capazes de induzir a geração de teratocarcinomas. Por se tratar de um tratamento alogênico, os animais doadores foram testados quanto a reações positivas para fragmentos de DNA de 185 pb e 410 pb (FCoV), 557 pb (FIV) 166 pb (FeLV), 167 pb (CPS), 173 pb (FHV-1), 205 pb (FCV), 170 pb (HFE) e 510 pb (micoplasma), não tendo sido detectada a presença dos patógenos. Desta forma, evita-se a possível transmissão dos mesmos aos animais receptores.

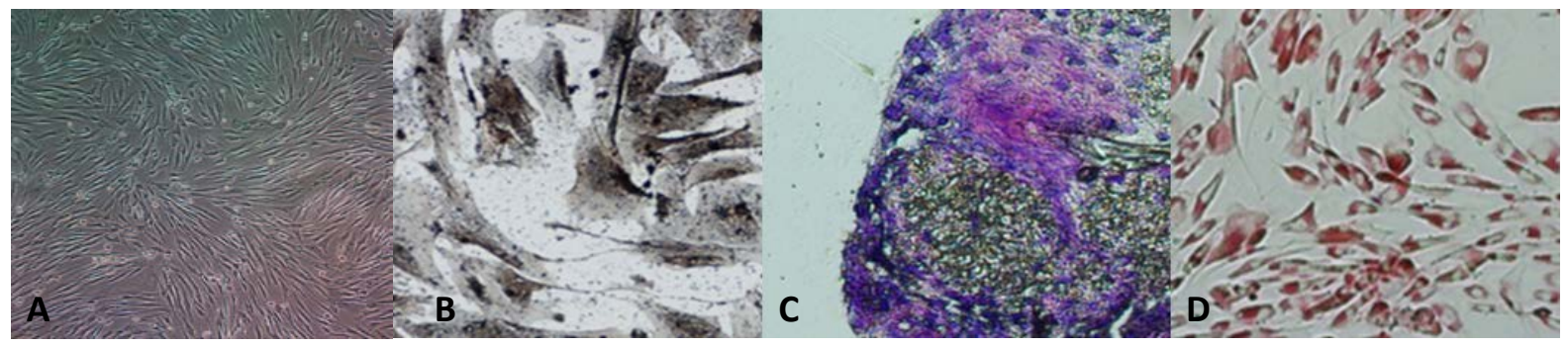

Figura 1 - Aspecto morfológico fibroblastoide $(A)$ das células-tronco isoladas a partir do tecido adiposo de felino (CPAMs-TAF). Imagens representativas das diferenciações osteogênica (B), condrogênica (C) e adipogênica (D) das CPAMs-TAF. Objetivas 10x (A), 20x (B,C) e 4x (D). 


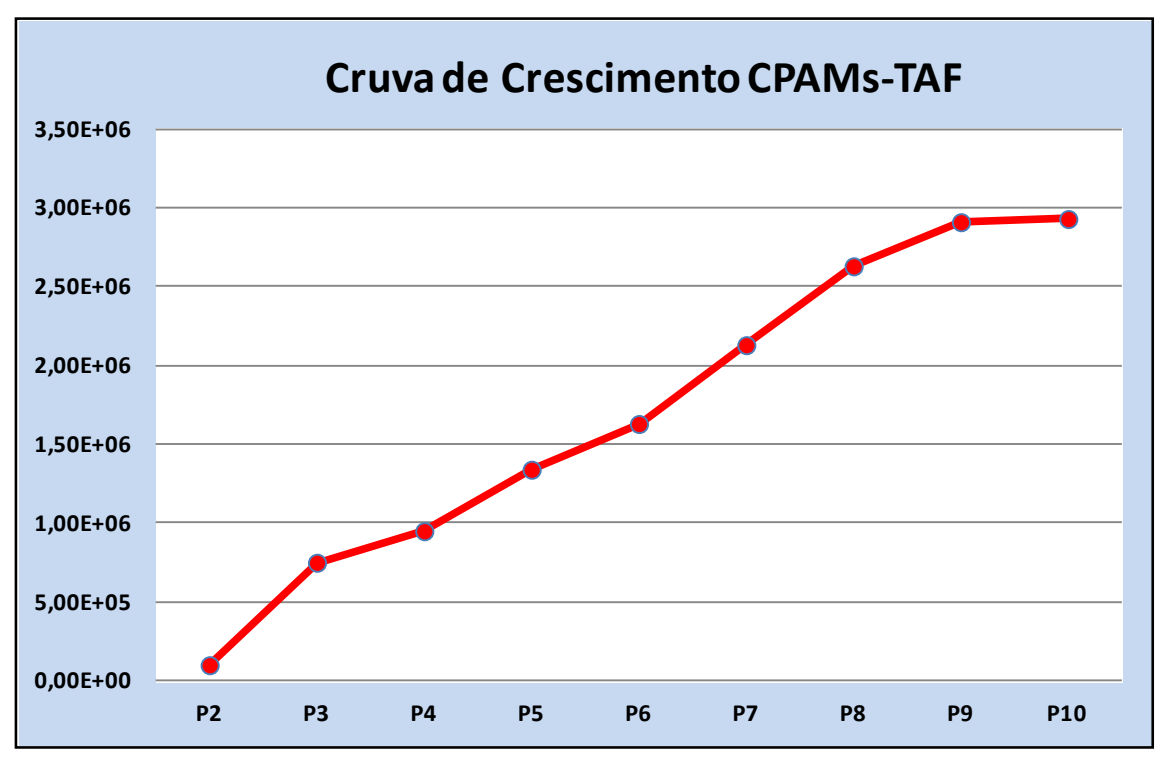

Figura 2 - Gráfico representativo da análise proliferativa das CPAMs-TAF. O crescimento das células foi analisado em um intervalo de 48 horas entre os repiques realizados por meio de ação enzimática.

Os felinos submetidos à terapia com CPAMs, foram identificados como no estágio $2(++)$ da doença renal crônica, conforme classificação da IRIS (IRIS, 2017). A análise bioquímica anterior ao início do tratamento revelou que os animais apresentavam valores de ureia entre $85 \mathrm{mg} / \mathrm{dL}$ a $132 \mathrm{mg} / \mathrm{dL}$ e creatinina de $1,93 \mathrm{mg} / \mathrm{dL}$ a $2,5 \mathrm{mg} / \mathrm{dL}$, sendo os valores referência de $10 \mathrm{mg} / \mathrm{dL}$ a $60 \mathrm{mg} / \mathrm{dL}$ e $0,5 \mathrm{mg} / \mathrm{dL}$ a $1,7 \mathrm{mg} / \mathrm{dL}$, respectivamente (Figura 3). Todos os animais apresentavam quadro clínico e laboratorial estável há pelo menos duas semanas. Por se tratar de um estudo piloto com animais de proprietários, um grupo controle não foi incluído.

\begin{tabular}{|c|c|c|c|c|c|c|c|c|}
\hline Gato número & $\begin{array}{c}\text { IRI } \\
\text { S }\end{array}$ & Idade & Raça & Peso & Ureia & Creatinina & Via & CT \\
\hline G1 & 2 & 9 anos & Persa & $6 \mathrm{Kg}$ & $132 \mathrm{mg} / \mathrm{dL}$ & $2,5 \mathrm{mg} / \mathrm{dL}$ & Endovenosa & 4 milhões \\
\hline G2 & 2 & 12 anos & SRD & $6 \mathrm{Kg}$ & $85 \mathrm{mg} / \mathrm{dL}$ & $2,0 \mathrm{mg} / \mathrm{dL}$ & Endovenosa & 4 milhões \\
\hline G3 & 2 & 13 anos & SRD & $4 \mathrm{~kg}$ & $95 \mathrm{mg} / \mathrm{dL}$ & $2,2 \mathrm{mg} / \mathrm{dL}$ & Endovenosa & 4 milhões \\
\hline G4 & 2 & 12 anos & SRD & $5 \mathrm{~kg}$ & $102,75 \mathrm{mg} / \mathrm{dL}$ & $2,3 \mathrm{mg} / \mathrm{dL}$ & Endovenosa & 4 milhões \\
\hline G5 & 2 & 12 anos & Siames & $5.5 \mathrm{~kg}$ & $116,0 \mathrm{mg} / \mathrm{dL}$ & $2,41 \mathrm{mg} / \mathrm{dL}$ & Endovenosa & 4 milhões \\
\hline G6 & 2 & 8 anos & SRD & $4.5 \mathrm{~kg}$ & $96.88 \mathrm{mg} / \mathrm{dL}$ & $1,93 \mathrm{mg} / \mathrm{dL}$ & Endovenosa & 4 milhões \\
\hline G7 & 2 & 4 anos & SRD & $6 \mathrm{Kg}$ & $102 \mathrm{mg} / \mathrm{dL}$ & $2,1 \mathrm{mg} / \mathrm{dL}$ & Endovenosa & 4 milhões \\
\hline
\end{tabular}

Figura 3 - Gatos classificados conforme IRIS estágio 2 receberam três doses de 4 × $10^{6}$ de CPAMs-TAF alogênicas por meio da via endovenosa. 
Os sete felinos com peso variando entre $4 \mathrm{~kg}$ e $6 \mathrm{~kg}$ e idade entre 4 e 13 anos, foram submetidos a três infusões com doses de $4 \times 10^{6}$ de CPAMs-TAF alogênicas por meio da via endovenosa com intervalos de 30 dias (Figura 4). As repetidas infusões de CPAMs-TAF alogênicas em baixas doses foram bem toleradas pelos animais (FU et al., 2013).

\begin{tabular}{|c|c|c|c|c|c|c|c|}
\hline Gato número & IRIS & Idade & Raça & Peso & Via & CT & DOSES \\
\hline G1 & 2 & 9 anos & Persa & $6 \mathrm{Kg}$ & Endovenosa & $4 \times 10^{6}$ & 3 \\
\hline G2 & 2 & 12 anos & SRD & $6 \mathrm{Kg}$ & Endovenosa & $4 \times 10^{6}$ & 3 \\
\hline G3 & 2 & 13 anos & SRD & $4 \mathrm{~kg}$ & Endovenosa & $4 \times 10^{6}$ & 3 \\
\hline G4 & 2 & 12 anos & SRD & $5 \mathrm{~kg}$ & Endovenosa & $4 \times 10^{6}$ & 3 \\
\hline G5 & 2 & 12 anos & Siames & $5.5 \mathrm{~kg}$ & Endovenosa & $4 \times 10^{6}$ & 3 \\
\hline G6 & 2 & 8 anos & SRD & $4.5 \mathrm{~kg}$ & Endovenosa & $4 \times 10^{6}$ & 3 \\
\hline G7 & 2 & 4 anos & SRD & $6 \mathrm{Kg}$ & Endovenosa & $4 \times 10^{6}$ & 3 \\
\hline
\end{tabular}

Figura 4 - Gatos classificados conforme IRIS estágio 2 que receberam três doses de 4 × $10^{6}$ de CPAMs-TAF alogênicas por meio da via endovenosa.

Estudos realizados em roedores evidenciaram a potencial eficácia de sucessivas aplicações de CPAMs para a supressão da inflamação intra-renal e fibrose, além de uma mais efetiva reparação tecidual (ALEXANDRE et al., 2009). Embora os resultados tenham sido obtidos utilizando células-tronco isoladas da medula óssea, ambas as fontes vêm demonstrando possuir o mesmo potencial terapêutico para doenças inflamatórias (YOO et al., 2009).

Os resultados preliminares obtidos por meio da adaptação do protocolo de roedores para felinos, sugerem que resultados similares poderão ser obtidos. Entretanto, algumas diferenças devem ser consideradas. Primeiramente, a infusão das CPAMs em ratos ocorre poucas semanas após a indução da lesão renal, ou seja, um período relativamente curto quando comparado ao processo natural (SEMEDO et al., 2009). Os felinos possuem um período de vida mais extenso, podendo levar meses ou anos para a doença renal ser diagnosticada. Segundo, os resultados em roedores foram obtidos por meio da utilização CPAMs autólogas, em detrimento às alogênicas aplicadas neste estudo. Estudos têm 
relatado dados controversos quanto à eficacia da terapia alogênica quando comparada à autóloga (ARZI et al., 2017). Em ratos acometidos por falha renal aguda, os resultados obtidos utilizando as CPAMs autólogas foram mais efetivos (TÖGEL et al., 2009). Os dados sugerem que as CPAMs autólogas sobrevivem mais tempo no organismo quando comparadas às alogênicas, o que resulta em uma menor efetividade destas (ALAGESAN; GRIFFIN, 2014). Porém, em humanos, os estudos clínicos vêm utilizando frequentemente as CPAMs alogênicas (GOZDZIK et al., 2015; WANG et al., 2014). Terceiro, neste estudo, diferentemente dos estudos em roedores, foram utilizadas CPAMs alogênicas criopreservadas, dada a manutenção da funcionalidade e imunogenicidade destas após serem expostas ao processo de criopreservação (QUIMBY et al., 2013).

A via endovenosa se caracteriza por ser de fácil execução, pouco invasiva e menos traumática, permitindo repetidas aplicações com o mínimo de efeitos colaterais (QUIMBY et al., 2016). Além disso, estudos demonstram que a adminsitração das CPAMs pela via endovenosa tende a reduzir, por meio de seu efeito parácrino, a probabilidade da ocorrência de insuficiência renal aguda isquêmica (TÖGEL et al., 2005). Entretanto, quando administradas em altas concentrações, estudos sugerem a possível formação de tromboembolismo pulmonar (MOLL et al., 2012).

Não foram identificados efeitos adversos nas infusões das CPAMs-TAF alogênicas como vômito, náusea, alteração da pressão arterial e/ou variação na frequência respiratória. As CPAMs-TAF alogênicas foram administradas em baixas concentrações e lentamente, uma vez que estudos em ratos demonstraram o risco de trombose pulmonar quando uma elevada concentração celular é administrada rapidamente pela via endovenosa (DEAK et al., 2010a, 2010b).

Os dados referentes às análises laboratoriais dos felinos não demonstraram variações estatisticamente relevantes nos valores de fósforo, albumina, sódio, potássio, cálcio, assim como nos índices referentes ao hemograma. A análise dos valores séricos, tanto da creatinina como da ureia, demonstraram uma redução estatisticamente significativa em ambos os índices (Figuras 5 e 6). 


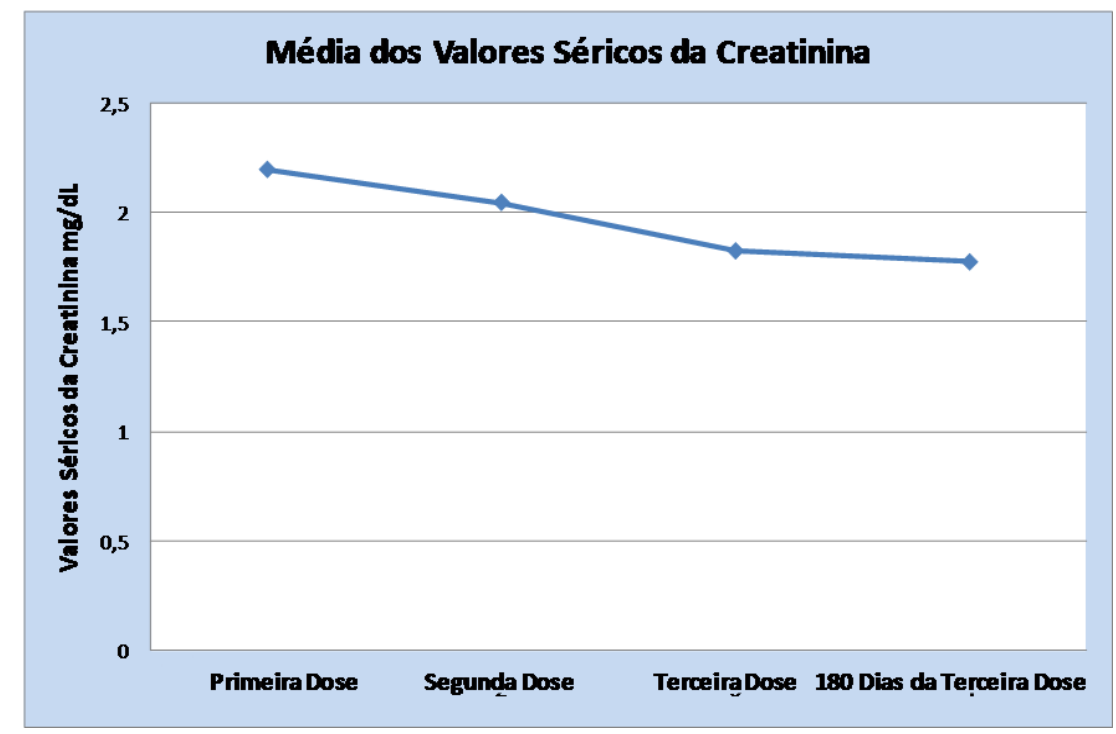

ANOVA

\begin{tabular}{|c|c|c|c|c|c|c|}
\hline Fonte da variação & $S Q$ & $g l$ & $M Q$ & $F$ & valor-P & Fcrítico \\
\hline Entre grupos & 1,024321 & 6 & 0,17072 & 3,759668 & 0,010660682 & 2,572712 \\
\hline Dentro dos grupos & 0,953575 & 21 & 0,045408 & & & \\
\hline Total & 1,977896 & 27 & & & & \\
\hline
\end{tabular}

Figura 5 - Análise da média dos valores séricos da creatinina dos felinos durante o transcorrer do estudo terapêutico dos gatos tratados com as CPAMs-TAF. 


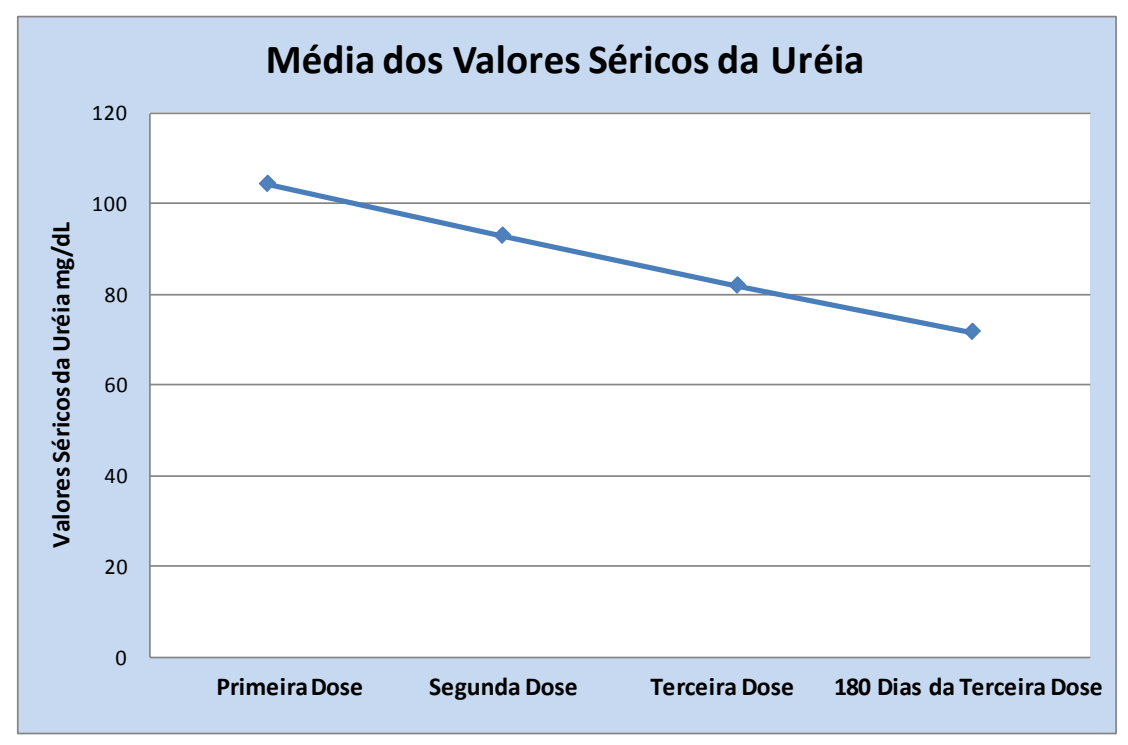

\begin{tabular}{|c|c|c|c|c|c|c|}
\hline Fonte da variação & $S Q$ & $g l$ & $M Q$ & $F$ & valor-P & F crítico \\
\hline Entre grupos & 4909,511 & & 6818,2519 & 2,656741 & 0,044581 & 2,572712 \\
\hline Dentro dos grupos & 6467,808 & & 21307,9908 & & & \\
\hline Total & 11377,32 & & 27 & & & \\
\hline
\end{tabular}

Figura 6 - Análise da média dos valores séricos da ureia dos felinos durante o transcorrer do estudo terapêutico dos gatos tratados com as CPAMs-TAF.

Durante o estudo foi observada uma redução dos valores séricos da creatinina ao longo do tratamento (Figura 7). Os dados obtidos 180 dias após a terceira aplicação das CPAMs-TAF demonstraram que seis gatos apresentaram tanto uma redução quanto a estabilidade dos valores. O Gato 5, demonstrou redução dos índices ao longo do tratamento, porém apresentou aumento dos valores séricos da creatinina após 180 dias. Embora os pacientes tenham apresentado redução dos valores séricos da creatinina, quatro deles atingiram os índices correspondentes aos valores de normalidade (Figura 8). 


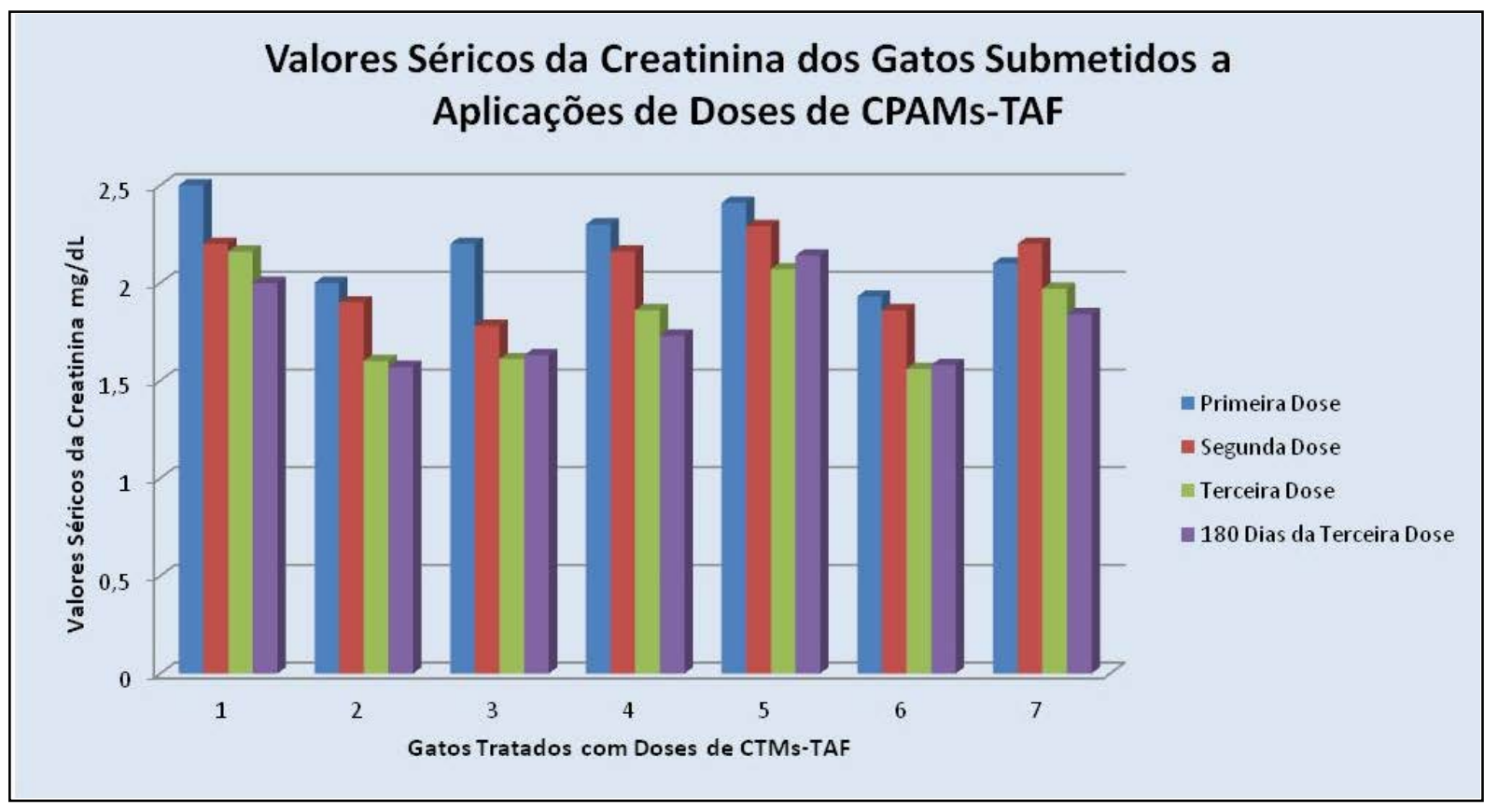

Figura 7 - Análise dos valores séricos da creatinina dos felinos durante o transcorrer da aplicação das doses de CPAMs-TAF

\begin{tabular}{|c|c|c|c|c|c|c|c|}
\hline DIAS & G1 & G2 & G3 & G4 & G5 & G6 & G7 \\
\hline $\mathbf{1}$ & $2,5 \mathrm{mg} / \mathrm{dL}$ & $2,0 \mathrm{mg} / \mathrm{dL}$ & $2,2 \mathrm{mg} / \mathrm{dL}$ & $2,3 \mathrm{mg} / \mathrm{dL}$ & $2,41 \mathrm{mg} / \mathrm{dL}$ & $1,93 \mathrm{mg} / \mathrm{dL}$ & $2,1 \mathrm{mg} / \mathrm{dL}$ \\
\hline $\mathbf{3 0}$ & $2,2 \mathrm{mg} / \mathrm{dL}$ & $1,9 \mathrm{mg} / \mathrm{dL}$ & $1,78 \mathrm{mg} / \mathrm{dL}$ & $2,16 \mathrm{mg} / \mathrm{dL}$ & $2,29 \mathrm{mg} / \mathrm{dL}$ & $1,86 \mathrm{mg} / \mathrm{dL}$ & $2,2 \mathrm{mg} / \mathrm{dL}$ \\
\hline $\mathbf{6 0}$ & $2,16 \mathrm{mg} / \mathrm{dL}$ & $1,6 \mathrm{mg} / \mathrm{dL}$ & $1,61 \mathrm{mg} / \mathrm{dL}$ & $1,86 \mathrm{mg} / \mathrm{dL}$ & $2,07 \mathrm{mg} / \mathrm{dL}$ & $1,56 \mathrm{mg} / \mathrm{dL}$ & $1,97 \mathrm{mg} / \mathrm{dL}$ \\
\hline $\mathbf{2 4 0}$ & $2,0 \mathrm{mg} / \mathrm{dL}$ & $1,57 \mathrm{mg} / \mathrm{dL}$ & $1,63 \mathrm{mg} / \mathrm{dL}$ & $1,73 \mathrm{mg} / \mathrm{dL}$ & $2,14 \mathrm{mg} / \mathrm{dL}$ & $1,58 \mathrm{mg} / \mathrm{dL}$ & $1,84 \mathrm{mg} / \mathrm{dL}$ \\
\hline
\end{tabular}

Figura 8 - Gatos classificados conforme IRIS estágio 2, envolvidos no estudo piloto tendo recebido doses de 4 $\times 10^{6}$ de CPAMs-TAF alogênicas por meio da via endovenosa.

Os dados relativos aos valores séricos da ureia obtidos ao longo do estudo, demonstraram redução dos índices tanto ao longo da aplicação das três doses de CPAMs-TAF quanto 180 dias após a terceira aplicação da última dose (Figura 9). Entretanto, apenas o gato 6 apresentou, após 180 dias, um valor de ureia, de 57,96 mg/dL, que está dento dos índices de referência, de $10 \mathrm{mg} / \mathrm{dL}$ a $60 \mathrm{mg} / \mathrm{dL}$. Os gatos 2 e 7 apresentaram, após 180 dias da última dose, valores próximos aos de referência $62,41 \mathrm{mg} / \mathrm{dL}$ e $65,4 \mathrm{mg} / \mathrm{dL}$, respectivamente (Figura 10). 


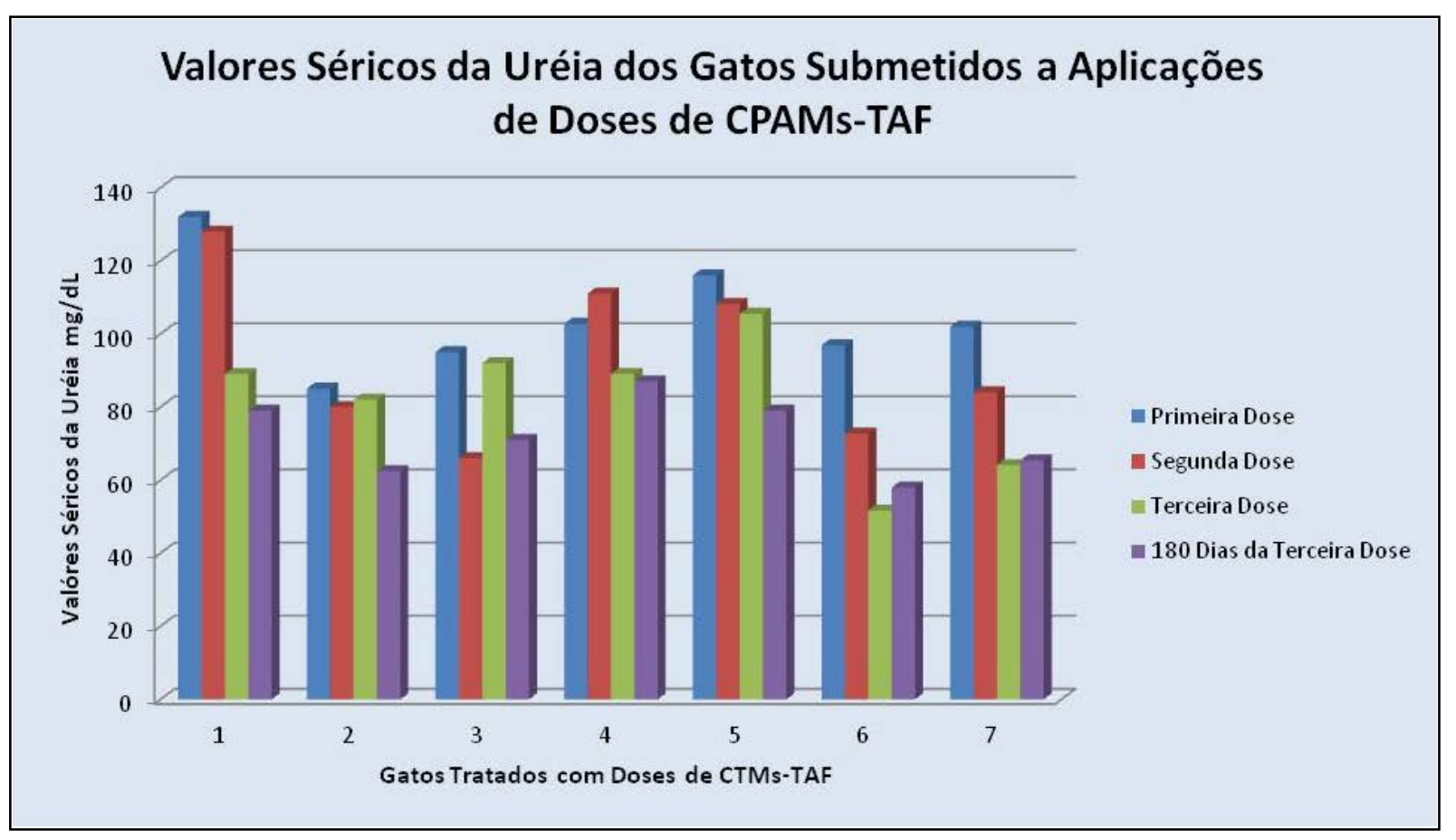

Figura 9 - Análise dos valores séricos da ureia dos felinos durante o transcorrer da aplicação das doses de CPAMs-TAF.

\begin{tabular}{|c|c|c|c|c|c|c|c|}
\hline DIAS & G1 & G2 & G3 & G4 & G5 & G6 & G7 \\
\hline $\mathbf{1}$ & $132,0 \mathrm{mg} / \mathrm{dL}$ & $85,0 \mathrm{mg} / \mathrm{dL}$ & $95,0 \mathrm{mg} / \mathrm{dL}$ & $102,75 \mathrm{mg} / \mathrm{dL}$ & $116,0 \mathrm{mg} / \mathrm{dL}$ & $96.88 \mathrm{mg} / \mathrm{dL}$ & $102,0 \mathrm{mg} / \mathrm{dL}$ \\
\hline $\mathbf{3 0}$ & $128,0 \mathrm{mg} / \mathrm{dL}$ & $80,0 \mathrm{mg} / \mathrm{dL}$ & $66,0 \mathrm{mg} / \mathrm{dL}$ & $111,0 \mathrm{mg} / \mathrm{dL}$ & $108,2 \mathrm{mg} / \mathrm{dL}$ & $72.7 \mathrm{mg} / \mathrm{dL}$ & $84,0 \mathrm{mg} / \mathrm{dL}$ \\
\hline $\mathbf{6 0}$ & $89,0 \mathrm{mg} / \mathrm{dL}$ & $82,0 \mathrm{mg} / \mathrm{dL}$ & $92,0 \mathrm{mg} / \mathrm{dL}$ & $89,0 \mathrm{mg} / \mathrm{dL}$ & $105,48 \mathrm{mg} / \mathrm{dL}$ & $51.61 \mathrm{mg} / \mathrm{dL}$ & $64,1 \mathrm{mg} / \mathrm{dL}$ \\
\hline $\mathbf{2 4 0}$ & $79,0 \mathrm{mg} / \mathrm{dL}$ & $62,41 \mathrm{mg} / \mathrm{dL}$ & $71,0 \mathrm{mg} / \mathrm{dL}$ & $87,0 \mathrm{mg} / \mathrm{dL}$ & $79,0 \mathrm{mg} / \mathrm{dL}$ & $57.96 \mathrm{mg} / \mathrm{dL}$ & $65,4 \mathrm{mg} / \mathrm{dL}$ \\
\hline
\end{tabular}

Figura 10 - Gatos classificados conforme IRIS estágio 2, envolvidos no estudo, que receberam três doses de $4 \mathrm{x}$ $10^{6}$ de CPAMs-TAF alogênicas por meio da via endovenosa.

A análise estatística da ANOVA determinou significância nos dados analisados referente às taxas de creatinina $(p=0,01)$ (Figura 5 ) e ureia $(p=0,04)$ (Figura 6$)$ demonstrando uma queda relevante nos valores. Todos os pacientes demonstraram melhora significativa da função renal após as infusões das CPAMs-TAF alogênicas sem aparentes efeitos adversos. Foi observada uma melhora clínica, ganho de apetite, aumento de peso e maior disposição em todos os gatos após a primeira aplicação. 


\section{CONCLUSÃO}

Os resultados do presente estudo são pioneiros ao demonstrar que a aplicação subsequente pela via endovenosa das CPAMs-TAF alogênicas e criopreservadas, isoladas a partir do tecido adiposo de felinos jovens e clinicamente saudáveis, resultou em uma significativa melhora dos pacientes. Estes resultados surgem como uma possível alternativa de tratamento para os felinos acometidos pela insuficiencia renal crônica, estágio 2 .

\section{ALLOGENEIC MULTIPOTENT ADULT PROGENITOR CELLS IN THE TREATMENT \\ OF KIDNEY DISEASE IN CATS}

\section{ABSTRACT}

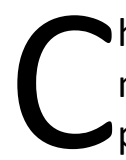

hronic kidney disease (CKD) is a syndrome characterized by impaired renal metabolism, which occurs dynamically and progressively, culminating in the loss of physiological functions of the kidneys. In this study, 7 felines, regardless of breed and sex, aged between 4 and 13 years, affected by stage 2 CKD, were treated with multipotent adult progenitor cells of feline adipose tissue (MAPCs-FAT) from a healthy donor animal. Three infusions were performed through the intravenous route, with an average interval of 30 days. The animals showed a significant improvement in renal function after MAPCs-FAT infusions without apparent adverse effects, clinical improvement, gain in appetite and increased disposal of animals, right after the first application. It is concluded that the therapy with MAPCs-FAT significantly contributed to the improvement of the quality of life of felines affected by chronic kidney disease stage 2 .

Keywords: MAPCs. Renal insufficiency. Cat. Cell therapy.

\section{CÉLULAS PROGENITORAS ADULTAS MULTIPOTENTES ALOGÉNICAS EN EL TRATAMIENTO DE FELINOS ACOMETIDOS POR LA ENFERMEDAD RENAL}

\section{RESUMEN}

a enfermedad renal crónica (ERC) es un síndrome caracterizado por el compromiso del metabolismo renal, que ocurre de forma dinámica y progresiva, culminando con la pérdida de las funciones fisiológicas de los riñones. Las células progenitoras adultas 
multipotentes (CPAM), presentes en todos los tejidos del organismo tienen como características principales el potencial de autorenovación y diferenciación celular. Cuando estas células son introducidas en el organismo las CPAM adquieren la morfología y la funcionalidad de cualquier tipo celular que constituía el tejido lesionado, lo que ha llevado a la su utilización en la medicina veterinaria. En este estudio, 7 felinos sin distinción de raza y sexo, con edades entre 4 años y 13 años, acometidos por la ERC, etapa 2, fueron tratados con células progenitoras adultas multipotentes de tejido adiposo de felinos (CPAMs-TAF), oriundas de un animal donante sano. Se realizaron tres infusiones por vía intravenosa, con un intervalo medio de 30 días. Los animales demostraron una significativa mejora de la función renal después de las infusiones de las CPAMs-TAF sin aparentes efectos adversos, habiéndose observado una mejora clínica, aumento del apetito y aumento de la disposición de los animales ya después de la primera aplicación. Se concluye que la terapia con las CPAM-TAF colaboró significativamente para la mejora de la calidad de vida de los felinos acometidos por la enfermedad renal crónica, etapa 2.

Palabras clave: CPAM. Insuficiencia renal. Gato. Terapia celular.

\section{REFERÊNCIAS}

ALAGESAN, S.; GRIFFIN, M. D. Autologous and allogeneic mesenchymal stem cells in organ transplantation: what do we know about their safety and efficacy? Current opinion in organ transplantation, v. 19, n. 1, p. 65-72, 2014.

ALEXANDRE, C. S.; VOLPINI, R. A.; SHIMIZU, M. H.; et al. Lineage-negative bone marrow cells protect against chronic renal failure. Stem Cells, v. 27, n. 3, p. 682-692, 2009.

ARZI, B.; CLARK, K. C.; SUNDARAM, A.; et al. Therapeutic Efficacy of Fresh, Allogeneic Mesenchymal Stem Cells for Severe Refractory Feline Chronic Gingivostomatitis. Stem cells translational medicine, v. 6, n. 8, p. 1710-1722, 2017.

BARBER, P. Diagnosis and management of chronic renal failure in the cat. In Practice, v. 25, n. 6, p. 306-313, 2003.

BUSSOLATI, B.; TETTA, C.; CAMUSSI, G. Contribution of stem cells to kidney repair. American journal of nephrology, v. 28, n. 5, p. 813-822, 2008.

CALDAS, H. C.; DE PAULA COUTO, T. A.;FERNANDES, I. M.; et al. Comparative effects of mesenchymal stem cell therapy in distinct stages of chronic renal failure. Clinical and Experimental Nephrology, v. 19, n. 5, p. 783-789, 2015.

CAPLAN, A. I.; DENNIS, J. E. Mesenchymal stem cells as trophic mediators. Journal of cellular biochemistry, v. 98, n. 5, p. 1076-1084, 2006. 
CAPLAN, A. I.; HARIRI, R. Body Management: Mesenchymal Stem Cells Control the Internal Regenerator. Stem cells translational medicine. v. 4, n. 7, p. 695-701, 2015.

COLLETTI, E. J.; AIREY, J. A.; LIU, W.; et al. Generation of tissue-specific cells from MSC does not require fusion or donor-to-host mitochondrial/membrane transfer. Stem Cell Research, v. 2 , n. 2 , p. $125-138,2009$.

DEAK, E.; SEIFRIED, E.; HENSCHLER, R. Homing pathways of mesenchymal stromal cells (MSCs) and their role in clinical applications. International reviews of immunology, v. 29, n. 5, p. 514-529, 2010a.

DEAK, E.; RÜSTER, B.; KELLER, L.; et al. Suspension medium influences interaction of mesenchymal stromal cells with endothelium and pulmonary toxicity after transplantation in mice. Cytotherapy, v. 12, n. 2, p. 260-264, 2010 b.

DONG, F.; CAPLAN, A. I. Cell transplantation as an initiator of endogenous stem cell-based tissue repair. Current Opinion in Organ Transplantation, v. 17, n. 6, p. 670-674, 2012.

ETTINGER, J. S.; FELDMAN, E. C. Tratado de Medicina Interna Veterinária: Doenças do Cão e do Gato. 5. ed. Rio de Janeiro: Guanabara Koogan, 2004.

FISCHER, J. R.; PANTALEO, V.; FRANCEY, T.; et al. Veterinary hemodialysis: advances in management and technology. The Veterinary Clinics of North America. Small Animal Practice, v. 34, n. 4, p. 935-967, 2004.

FU, X. M.; YAMAWAKI-OGATA, A.; OSHIMA, H.; et al. Intravenous administration of mesenchymal stem cells prevents angiotensin II-induced aortic aneurysm formation in apolipoprotein E-deficient mouse. Journal of Translational Medicine, v. 11, p. 175, 2013.

GOZDZIK, J.; REWUCKA, K.; KRASOWSKA-KWIECIEN, A.; et al. Adoptive therapy with donor lymphocyte infusion after allogenic hematopoietic SCT in pediatric patients. Bone Marrow Transplantation, v. 50, n. 1, p. 51-55, 2015.

GRAUER, G. F. Early detection of renal damage and disease in dogs and cats. The Veterinary Clinics of North America. Small Animal Practice, v. 35, n. 3, p. 581-596, 2005.

HOPPER, K.; MEHL, M. L.; KASS, P. H.; et al. Outcome after renal transplantation in 26 dogs. Veterinary Surgery, v. 41, n. 3, p. 316-327, 2012.

IRIS - INTERNATIONAL RENAL INTEREST SOCIETY. IRIS staging of CKD (modified 2017). Disponível em: <http://www.iris-kidney.com/pdf/IRIS_2017_Staging_of_CKD_09May18.pdf>

LEE, S. R.; LEE, S. H.; MOON, J. Y.; et al. Repeated administration of bone marrow-derived mesenchymal stem cells improved the protective effects on a remnant kidney model. Renal failure, v. 32, n. 7, p. 840-848, 2010. 
MARTIN, D. R.; COX, N. R.; HATHCOCK, T. L.; et al. Isolation and characterization of multipotential mesenchymal stem cells from feline bone marrow. Experimental Hematology, v. 30, n. 8, p. 879-886, 2002.

MCGROTTY, Y. Diagnosis and management of chronic kidney disease in dogs and cats. In Practice, v. 30, n. 9, p. 502-507, 2008.

MOLL, G.; RASMUSSON-DUPREZ, I.; VON BAHR, L.; et al. Are therapeutic human mesenchymal stromal cells compatible with human blood? Stem Cells, v. 30, n. 7, p. 15651574, 2012.

PENG X.; XU H.; ZHOU Y.; et al. Human umbilical cord mesenchymal stem cells attenuate cisplatin induced acute and chronicrenal injury. Experimental biology and medicine, v. 238, n. 8, p. 960-970, 2013.

PRESSLER, B. M. Clinical approach to advanced renal function testing in dogs and cats. The Veterinary Clinics of North America. Small Animal Practice, v. 43, n. 6, p. 1193-1208, 2013.

QIN, Z. H.; XU, J. F.; QU, J. M.; et al. Intrapleural delivery of MSCs attenuates acute lung injury by paracrine/endocrine mechanism. Journal of cellular and molecular medicine, v. 16, n. 11, p. 2745-2753, 2012.

QUEIROZ, L. L. Tratamento da doença renal crônica em pequenos animais. Goiânia: UFG, 2013. 54p. Dissertação (Disciplina Seminários Aplicados), Programa de Pós-Graduação em Ciência Animal, Escola de Veterinária e Zootecnia, Universidade Federal de Goiás; 2013.

QUIJADA, P.; SALUNGA, H. T.; HARIHARAN, N.; et al. Cardiac Stem Cell Hybrids Enhance Myocardial Repair. Circulation research, v. 117, n. 8, p. 695-706, 2015.

QUIMBY, J. M.; WEBB, T. L.; HABENICHT, L. M.; et al. Safety and efficacy of intravenous infusion of allogeneic cryopreserved mesenchymal stem cells for treatment of chronic kidney disease in cats: results of three sequential pilot studies. Stem cell research $\&$ therapy, v. 4 , n. 2, p. $48,2013$.

QUIMBY, J. M.; WEBB, T. L.; RANDALL, E.; et al. Assessment of intravenous adipose-derived allogeneic mesenchymal stem cells for the treatment of feline chronic kidney disease: a randomized, placebo-controlled clinical trial in eight cats. Journal of feline medicine and surgery, v. 18, n. 2, p. 165-171, 2016.

REINDERS, M. E.; DE FIJTER, J. W.; RABELINK, T. J. Mesenchymal stromal cells to prevent fibrosis in kidney transplantation. Current opinion in organ transplantation, v. 19, n. 1, p. 54-59, 2014. 
SANTOS, E. J. C. Análise da Aplicação Terapêutica das Células Tronco na Medicina Veterinária. Revista Científica Multidisciplinar Núcleo do Conhecimento, Ano 2, v. 1, p. 269295, 2017.

SEMEDO, P.; CORREA-COSTA, M.; ANTONIO CENEDEZE, M.; et al. Mesenchymal stem cells attenuate renal fibrosis through immune modulation and remodeling properties in a rat remnant kidney model. Stem Cells, v. 27, n. 12, p. 3063-3073, 2009.

SUZUKI, E.; FUJITA, D.; TAKAHASHI, M.; et al. Adult stem cells as a tool for kidney regeneration. World journal of nephrology, v. 5, n. 1, p. 43-52, 2016.

TÖGEL, F.; HU, Z.; WEISS, K.; et al. Administered mesenchymal stem cells protect against ischemic acute renal failure through differentiation-independent mechanisms. American journal of physiology. Renal physiology, v. 289, n. 1, p. 31-42, 2005.

TÖGEL, F.; COHEN, A.; ZHANG, P.; et al. Autologous and allogeneic marrow stromal cells are safe and effective for the treatment of acute kidney injury. Stem cells and development, $v$. 18, n. 3, p. 475-485, 2009.

YOO, K. H.; JANG, I. K.; LEE, M. W.; et al. Comparison of immunomodulatory properties of mesenchymal stem cells derived from adult human tissues. Cellular immunology, v. 259, n. 2, p. 150-156, 2009.

WANG, P.; LI, Y.; HUANG, L.; et al. Effects and safety of allogenic mesenchymal stem cell intravenous infusion in active ankylosing spondylitis patients who failed NSAIDs: a 20-week clinical trial. Cell Transplantation, v. 23, n. 10, p. 1293-1303, 2014. 